\author{
Л.М. Артюшин ${ }^{1}$, О.А. Кононов ${ }^{1}$, В.Б. Срко ${ }^{1}$ \\ ${ }^{1}$ Державний науково-дослідний інститут авіаиії, Київ
}

\title{
ВИЗНАЧЕННЯ РЕЗУЛЬТУЮЧОЇ МНОЖИНИ ВАРІАНТІВ ПРИ БАГАТОКРИТЕРІЙНОМУ ВИБОРІ СКЛАДУ БОРТОВОГО ОБЛАДНАННЯ БОЙОВИХ ЛІТАКІВ ДЛЯ ЇХ МОДЕРНІЗАЦІї
}

Визначено невідповідність між практичною потребою у забезпеченні обтрунтованості вибору складу сучасного бортового обладнання для модернізаџії бойових літаків та обмеженими можливостями існуючих методик вибору, щзо визначає актуальність даної статті. В роботі наведено використання науковометодичного апарату багатокритерійного вибору при визначенні складу бортового обладнання бойових літаків для розширення їх бойових можливостей иляхом модернізачії. Запропоновано науково-методичний підхід з визначення у багатокритерійному просторі результуючої множини варіантів складу бортового обладнання бойових літаків при їх модернізаиії.

Ключові слова: багатокритерійний вибір, модернізація, літальний апарат, Парето-множина, результуюча множина.

\section{Вступ}

Модернізація бойових літальних апаратів (ЛА), а саме: літаків типу Су-27, Су-24, МиГ-29, Су-25 тощо, шляхом оновлення складу бортового обладнання (БО) (систем радіоелектронного обладнання, систем авіаційного обладнання, систем авіаційного озброєння) $є$ сучасною світовою тенденцією, економічно вигідним напрямом підвищення бойових спроможностей вітчизняних Повітряних Сил. Для України в умовах зовнішньої воєнної та економічної агресій цей шлях є особливо важливим.

На сьогодні в Україні створена та успішно функціонує система модернізації бойових літальних апаратів. Вітчизняні авіаційні ремонтні підприємства опанували та виконують модернізацію більшості типів бойових ЛА за першим, так званим "малим", варіантом модернізації. Набутий досвід свідчить, що рівень відповідальності за результати вибору того чи іншого варіанту складу бортового обладнання (БО) для проведення модернізації потребує обгрунтованості.

Необхідно зазначити, що наступний етап (другий варіант модернізації) ще більш складний та об'ємний i, вочевидь, вже потребує сучасних методичних підходів до вибору складу БО бойових ЛА для їх модернізації.

Прискорене поширення мікропроцесорної елементної бази, що відбувається протягом останніх років, суттєво збільшує кількість розробників, кількість конкурентних зразків БО для вибору.
В цих умовах, вже найближчим часом вибір складу БО буде необхідно проводити серед багатьох десятків варіантів, а існуючі методики вибору не дозволять забезпечити його обгрунтованість.

Аналіз попередніх досліджень $[1$, с. $85 \ldots 90 ; \quad 2$, с. $55 \ldots 59 ;$ 3, с. $124 \ldots 284$; 4 , c. $144 \ldots 189 ; \quad 5$, c. $7 \ldots 52,192 \ldots 222$; 6 , c. $12 \ldots 52 ; 7$, с. $7 \ldots 22,67 \ldots 79 ; 8$, с. $7 \ldots 20$; 9 , c. $32 \ldots 56 ; 10$, c. $47 \ldots 62 ; 11$, c. $2 \ldots 12$; 12 , с. $43 \ldots 65,173 \ldots 189 ; \quad 13$, с. $8 \ldots 78$; 14 , с. $1593 \ldots 1601 ; 15$, с. $5 \ldots 10 ; 16]$ показує, що методики прямого перебору-порівняння варіантів не $є$ результативними при великій кількості конкурентних варіантів, а методики, що базуються на застосуванні згорток та пріоритетів часткових критеріїв вибору, “цільових (ідеальних) точок” або експертів, передбачають введення додаткової зовнішньої інформації (вагових коефіцієнтів згорток, кількісного співвідношення пріоритетів, значень цільових точок, кола обраних експертів), що фактично обумовлює результати вибору та вкрай негативно впливає на його обгрунтованість (рис. 1). В цих методиках суб'єктивний характер додаткової інформації принципово обмежує можливість отримання обгрунтованого результату вибору у випадку великої кількості варіантів. 


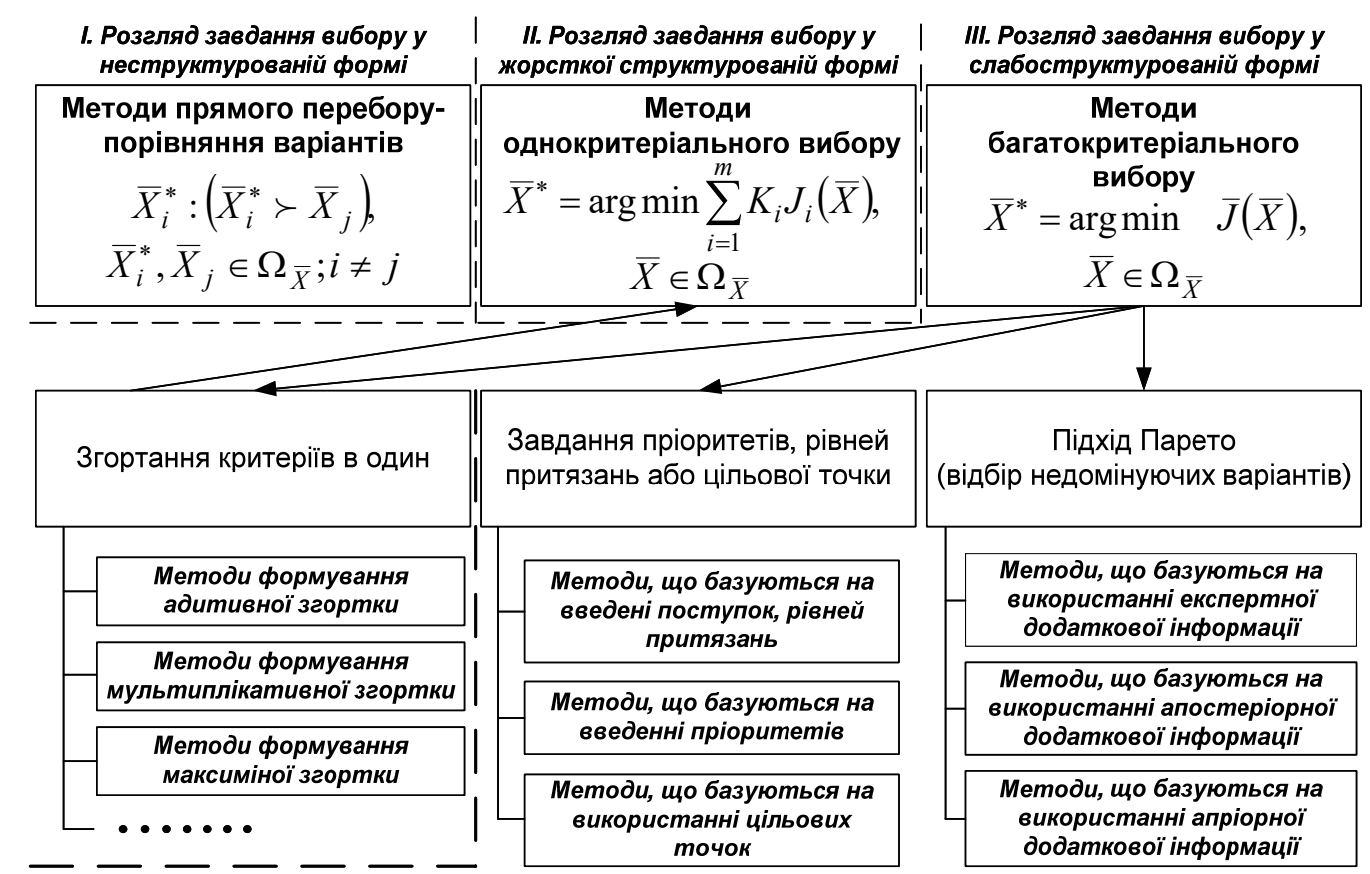

Рис.1. Структура існуючого науково-методичного апарату вибору. Джерело: розроблено авторами.

Слід зазначити, що методики вибору складу БО, які застосовуються при модернізації літаків i вертольотів цивільної авіації, базуються на критеріях економічної ефективності та не здатні адекватно врахувати специфічні вимоги до бойових ЛА.

Неможливість забезпечення обгрунтованості вибору варіанту складу БО для проведення модернізації бойових ЛА вкрай негативно вплине на виконання державної програми модернізації парку бойових ЛА вже у найближчій перспективі.

Методологія багатокритерійного вибору не заперечує можливості подолання зазначеного недоліку шляхом врахування специфічних особливостей бойових ЛА, як складних комплексів озброєння та військової техніки. Але, попри наявність потужного теоретичного базису у цьому напрямі, прикладне питання його використання для модернізації бойових ЛА практично не відображено ні в закордонних, ні у вітчизняних джерелах.

Це визначає об'єктивну потребу у забезпеченні обгрунтованості вибору складу БО бойових ЛА для їх модернізації, яка з часом буде тільки посилюватися.

Системне подолання цієї ситуації полягає, на наш погляд, у розв'язанні актуального науково-технічного завдання 3 реалізації багатокритерійного підходу до проблематики вибору $[1,2]$. У цьому підході функція методичного апарату зводиться до виділення з множини можливих варіантів вибору тих альтернатив, що не мають переваг перед іншими, а функція безпосереднього вибору серед залишених конкурентних варіантів покладається на особу, що відповідає за прийняття кінцевого рішення - Замовнику.

Отже, метою статті $є$ представлення результатів особистих досліджень авторів щодо отримання результуючих варіантів в множині Парето, що базуються на застосуванні відомих методів використання апріорної інформації для формування множини результуючих варіантів складу БО бойових ЛА при їх модернізації.

Методологія, що використовується у статті, є подальшим розвитком відомої наукової школи 3 розв'язання задач векторної оптимізації авіаційно-космічної спрямованості [3...6].

\section{Виклад основного матеріалу}

Задача вибору БО формалізована таким чином: приймемо, що модернізація бойового ЛА буде полягати у заміні $n$ видів БО на нові зразки $3 m$ можливих різновидів кожного зразка БО.

Кожний з можливих видів зразків БО для заміни визначається $M$ показниками, які описують його тактико-технічні та технікоекономічні властивості.

При цьому варіант складу БО для модернізації це - сукупність $n$ зразків БО 3 $m$ можливих альтернатив для вибору кожної системи, тактико-технічні та техніко-економічні характеристики яких $\bar{A}_{i}$ визначаються $a_{j}$ показниками $(j=1 \ldots M)$ окремих зразків, які 
включено у даний варіант складу.

Отже, $n$-компонентний вектор варіанту складу БО $\bar{X}_{i}$ це $\bar{X}_{i}=\left[x_{1}, x_{2}, \ldots, x_{n}\right]^{T}$.

$N$ - елементна сукупність можливих варіантів складу БО складає $\Omega_{\bar{x}}$ множину можливих варіантів.

Кожний вектор $\bar{X}_{i}$ однозначно визначається вектором показників $\bar{A}_{i}=\left[a_{1}, a_{2}, \ldots, a_{n \cdot M}\right]^{T}$, де $n \cdot M-$ кількість характеристик, які визначають властивості кожного з варіантів БО, що складають множину $\Omega_{\bar{X}}$.

$I$ - система переваг особи, що здійснює вибір (ОЗВ), за якою здійснюється вибір варіантів, тобто множина відношень переваги одного варіанту БО над іншим $\left(\bar{X}_{i} \succ \bar{X}_{j}\right)$ за їх показниками $\bar{A}_{i}, \bar{A}_{j},[7,8]$. Відповідно до цього відношення, переваги $i$-го варіанту БО над $j$-м варіантом $\bar{X}_{i} \succ \bar{X}_{j}$ еквівалентно відношенню $\bar{A}_{i} \succ \bar{A}_{j}$. Характеристики $A_{i}$ однозначно повністю визначають властивості варіанта БО та є достатніми для здійснення вибору.

Передбачається, що вибір здійснює ОЗВ (окрема людина або колектив), який підлеглий визначеній меті. Система переваг ОЗВ I належить множині Паретоваріантів $\Omega_{\bar{X}}^{*} \in \widetilde{\Omega}_{\bar{X}}$ та не потребує для визначення застосування зовнішньої додаткової інформації $I_{d o p}$. Отже, $\Omega_{\bar{X}}^{*}=f(I)$.

Завдання вибору складу БО в процесі модернізації бойового ЛА полягає у визначенні такої множини варіантів БО $\Omega_{\bar{X}}^{*}\left(\Omega_{\bar{X}}^{*} \in \widetilde{\Omega}_{\bar{X}}\right)$, які $є$ найкращими у множині $\Omega_{\bar{X}}$ відносно системи переваг (преференцій) ОЗВ $I$ без залучання зовнішньої додаткової інформації $I_{d o p}$.

Задача дослідження набуває вигляду

$$
\Omega^{*}{ }_{\bar{X}}:\left\{\begin{array}{c}
\Omega \\
\bar{X} \in \widetilde{\Omega}_{\bar{X}} ; \\
\Omega_{\bar{X}} \neq f\left(I_{d o p}\right) ;
\end{array}\right.
$$

де $\widetilde{\Omega}_{\bar{X}}-N$ - елементна множина Парето-варіантів складу БО.

Для цих умов формалізована постановка задачі буде виглядати $\left\langle\Omega_{\bar{X}}, I\right\rangle$.

Задачу (1) можна формалізувати як задачу вибору із заданої множини $\Omega_{\bar{X}}$ можливих варіантів складу бортового обладнання $\bar{X}_{i}$ такої підмножини варіантів $\Omega_{\bar{X}}^{*}$, які $\epsilon$ найкращими відносно системи переваг ОЗВ $I$, тобто множини відношень переваги одного варіанту над іншим $\left(\bar{X}_{i} \succ \bar{X}_{j}\right)$ за їх показниками $\bar{A}_{i}, \bar{A}_{j}$, без залучення додаткової зовнішньої інформації $I_{d o p}$.

Розв'язання (1) здійснюється за таких припущень та обмежень:

по-перше, розглядається вибір за умов відсутності випадковостей, невизначеностей, неповноти інформації про характеристики зразків БО;

по-друге, розглядається можливість опису всіх властивостей БО однією системою тактикотехніко-економічних характеристик;

по-третє, розглядаються конкурентні за технічними можливостями та вартісними характеристиками зразки БО, тобто серед них немає таких, що мають перевагу перед іншими за усіма характеристиками $\bar{a}_{j}$;

в четверте, не розглядається можливість зведення системи переваг ОЗВ до задачі 3 забезпечення економічної ефективності.

Отже, до розгляду прийнято задачу багатокритерійного вибору складу БО для модернізації бойових ЛА в умовах кінцевої множини варіантів БО, повної початкової детермінованої інформації про варіанти i відсутності зовнішньої додаткової інформації. Істотною вимогою до іï розв'язання $\epsilon$ намагання отримати процедури, що придатні для прикладного застосування, а не абстрактний математичний метод. Саме тому важливим $\epsilon$ врахування обчислювальних обмежень і задовольняння вимогам до модернізації бойового ЛА для отримання невеликої за потужністю результуючої множини складів БО $\Omega_{\bar{X}}^{*}$ для вибору.

Згідно з методологією багатокритерійного вибору [7...9], пошук множини Парето, тобто множини ефективних рішень відповідно до заданого векторного критерію, вже $\epsilon$ математично обгрунтованим достатнім розв'язанням поставленої задачі. Для його подальшої конкретизації, згідно 3 принципом Еджворта-Парето [7...9], необхідним $є$ використання додаткової інформації.

Формати введення додаткової інформації можуть бути різними, але для забезпечення інтересів ОЗВ, а не інтересів зовнішніх сторін, важливим $\epsilon$ врахування принципових

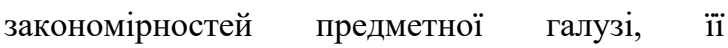
властивостей і особливостей.

Для цього пропонується використати характерну особливість множини Парето для умов задачі вибору БО для модернізації бойового ЛА, а саме ту, що задачі багатокритерійного вибору містять, як правило, не одне, а декілька результуючих рішень. За цією причиною i виникає задача звуження області Парето, що полягає в обранні того або 
іншого складу варіанта БО бойового ЛА для модернізації в якості “кращого” для ОЗВ.

У загальній постановці задача формування результуючої множини варіантів складу БО бойового ЛА для їх модернізації полягає у визначенні одного або декількох варіантів зі вхідної множини допустимих варіантів (рішень) $\Omega$ д. Приймемо, що множина обраних варіантів - це $F_{3}\left(A_{k}\left(\bar{X}_{i}\right)\right)$. Вочевидь, $A_{k}\left(\bar{X}_{i}\right) \subset \Omega_{д}$. Отже, в задачі вибору існує множина $A_{k}\left(\bar{X}_{i}\right)$, що містить принаймні два елементи, а треба відшукати деяку непусту підмножину $F_{3}\left(A_{k}\left(\bar{X}_{i}\right)\right)$.

Для того, щоб отриманий результат найбільше відповідав меті вибору, необхідно враховувати “смаки” та “уподобання" ОЗВ, які у той або інший спосіб розкривають зміст “найкращого” рішення. Іноді “уподобання” ОЗВ вдається виразити деяким тривіальним чином, наприклад, таким: варіант $a^{\prime}$ переважніше $a^{\prime \prime}$ тоді та тільки тоді, коли оцінка $A_{k}\left(\bar{X}_{i}\right)^{\prime}$ першого варіанту суворо більше оцінки $A_{k}\left(\bar{X}_{i}\right)^{\prime \prime}$ другого варіанту, де $A_{k}$ - цільова функція (критерій оптимальності), що визначена на множині $\Omega_{д}$. У цьому випадку множину $A_{k}\left(\bar{X}_{i}\right)$ складено 3 елементів, які забезпечують максимальне значення

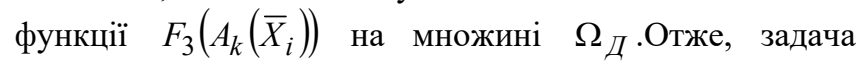
вибору перетворюється у звичайну оптимізаційну задачу, для якої розроблено значний арсенал методів розв'язання.

У разі, коли необхідно формування результуючої множини варіантів складу БО або визначення одного варіанту для модернізації бойового ЛА, немає змоги відображати “уподобання” ОЗВ наведеним вище чином.

В задачі багатокритерійного вибору варіантів складу БО для модернізації бойового ЛА функції “цільової” “витратної”, та “льотної” компонент, які визначені на множині $\Omega_{Д}$ і утворюють векторний критерій $\bar{J}\left(\bar{X}_{i}\right)$ [2]. При цьому зазвичай доповнюють, що для ОЗВ бажано знайти екстремум кожного 3 показників $\bar{a}_{j}$ конкретних зразків БО.

Ця вимога точно виражена у формі аксіоми Парето: якщо оцінка одного з варіантів не гірше оцінки за всіма компонентами іншого, причому принаймні один 3 них - суворо краще, то перший варіант має перевагу над другим, тобто

$$
\begin{gathered}
\left(\left(A_{k}\left(\bar{X}_{i}\right)\right),\left(A_{k}\left(\bar{X}_{i}\right)\right)^{\prime \prime}\right) \in \Omega_{Д}, \quad J_{k}\left(A_{k}\left(\bar{X}_{i}\right)\right)^{\prime} \geq J_{k}\left(A_{k}\left(\bar{X}_{i}\right)\right)^{\prime \prime}, \\
\left(k_{k} \overline{\overline{1}, M}\right) ; \quad \exists j \in\left\{1,2, \ldots, N_{\Pi}\right\}: \\
\left.J_{k}\left(A_{k}\left(\bar{X}_{i}\right)\right)^{\prime}>J_{k}\left(A_{k}\left(\bar{X}_{i}\right)\right)^{\prime \prime} \Rightarrow\left(A_{k}\left(\bar{X}_{i}\right)\right)^{\prime}\right)_{\overline{\Omega_{\bar{X}}}}^{\succ}\left(A_{k}\left(\bar{X}_{i}\right)\right)^{\prime \prime} .
\end{gathered}
$$

Під час розв'язання задачі з відшукання результуючої множини варіантів складу БО бойового ЛА для модернізації відносини вигляду $\bar{X}_{i} \succ \bar{X}_{j}$ зазвичай невідомі, тому прийняття аксіоми Парето означає наявність деякої інформації про наведені відносини. Така інформація дає підстави для пари варіантів $\left(A_{k}\left(\bar{X}_{i}\right)\right)^{\prime},\left(A_{k}\left(\bar{X}_{i}\right)\right)^{\prime \prime}, \quad$ що задовольняють умові у лівій частині імплікації (2), виключити другий варіант як “завідомо непридатний”.

При розв'язанні задачі вибору варіанту складу БО бойового ЛА варіант БО, що не обирається у будь-який парі, може бути обраним у множині $\Omega$ д . Однак при розв'язанні даної задачі необхідним є виконання наступної передумови, що сформульовано у аксіомі виключення.

Аксіома виключення: варіант, що не обирається у будь-якої парі, не повинен входити у множину обраних та у вхідну множину допустимих варіантів

$$
\begin{gathered}
\left(\left(A_{k}\left(\bar{X}_{i}\right)\right)^{\prime}, \quad\left(A_{k}\left(\bar{X}_{i}\right)\right)^{\prime \prime}\right) \in \Omega_{\mathcal{L}},\left(A_{k}\left(\bar{X}_{i}\right)\right)^{\prime} \underset{\widetilde{\Omega}_{\bar{X}}}{\succ}\left(A_{k}\left(\bar{X}_{i}\right)\right)^{\prime \prime} \Rightarrow \\
\Rightarrow\left(A_{k}\left(\bar{X}_{i}\right)\right)^{\prime} \in \widetilde{\Omega}_{\bar{X}}\left(A_{k}\left(\bar{X}_{i}\right)\right) .
\end{gathered}
$$

Це визначає, що дану вимогу варто розглядати як певне обмеження на множину рішень, які обираються, а саме: будь-яка множина рішень, що обирається, яким би способом іiі не було виділено із множини допустимих рішень $\Omega_{Д}$, не повинна містити жодного такого рішення, для якого може найтися більш краще рішення.

Якщо задано не один, а відразу кілька критеріїв оптимальності, то для визначеності кожного $з$ них необхідно вказати “напрямок зацікавленості” ОЗВ.

Наведені вище аксіоми дають можливість встановити, що варіанти, які обираються, не можуть знаходитись за межами множини Парето $\widetilde{\Omega}_{\bar{X}}$, та при цьому результуючим може бути будь-який оптимальний за Парето варіант БО бойового ЛА.

Загально відомо, що звуження множини Парето $є$ можливе при наявності тієї або іншої додаткової інформації про багатокритеріальну задачу, що розв'язується. Зазвичай ОЗВ подібну інформацію замінює 
деякими евристичними міркуваннями або визначеними “правдоподібними” припущеннями, які дозволяють звужувати множину “найкращих" варіантів складу БО. Характерною ознакою евристичних методів $є$ відсутність можливості чіткого опису такого класу задач багатокритеріального вибору, при розв'язанні яких гарантовано отримується бажаний результат. 3 даної точки зору аксіоматичні підходи $є$ більш обгрунтованими, оскільки аксіоматика, що використовується, суворо визначає клас задач, для розв'язання яких вона призначена.

3 метою отримання практично важливого рішення задачі багатокритеріального вибору без залучення зовнішньої додаткової інформації запропоновано [7] розглянути для кожного варіанту, що належить множині Парето $\bar{X}_{i} \in \widetilde{\Omega}_{\bar{X}}$, інтегральну характеристику

$$
\rho\left(\bar{X}_{i}\right)=\sum_{j=1}^{\tilde{N}} \sqrt{\sum_{k=1}^{R}\left(J_{k}^{u}\left(\bar{X}_{i}\right)-J_{k}^{u}\left(\bar{X}_{j}\right)\right)^{2}},
$$

де $\tilde{N}$ - це кількість елементів у множині Парето.

Характеристика (4) $є$ сумарною евклідовою відстанню у $M$ - мірному просторі між точкою, що відповідає варіанту $\bar{X}_{i}$, і точками, що відповідають іншим варіантам, та відображає його принципові особливості (рис.2.).

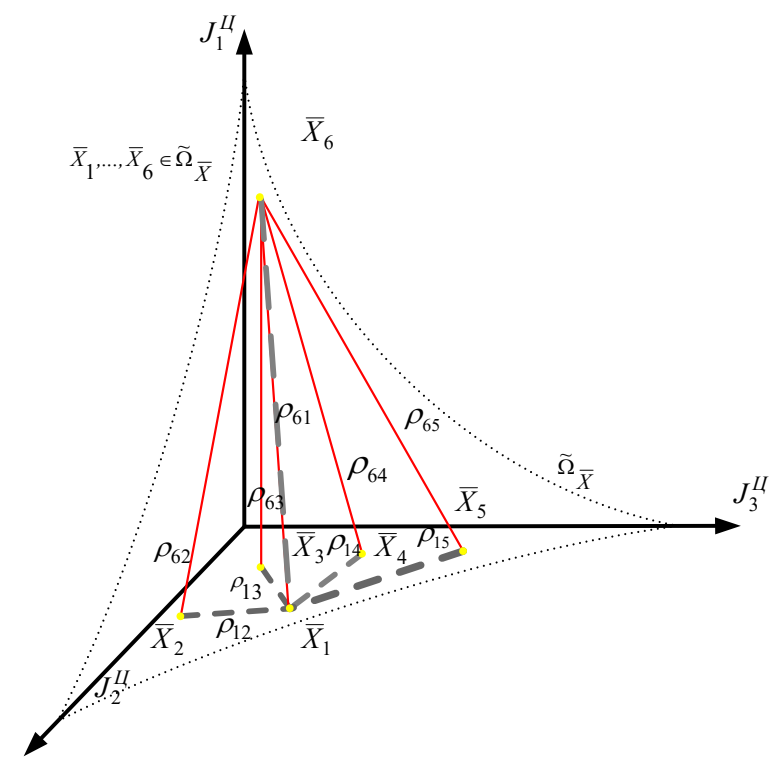

Рис. 2. Визначення варіанту складу БО бойового ЛА за умови врахування результуючої характеристики. Джерело: розроблено авторами.

Проведений аналіз результатів розрахункових експериментів відповідно до (4) свідчить, що можна виділити дві підмножини альтернатив. Перша 3 відносно малим значенням параметра (4), інша - 3 відносно великим значенням зазначеного параметра.

$$
\begin{gathered}
\text { Для наведеного прикладу отримуємо } \\
\rho\left(\bar{X}_{6}\right)=\rho_{61}+\rho_{62}+\rho_{63}+\rho_{64}+\rho_{65} ; \\
\rho\left(\bar{X}_{1}\right)=\rho_{11}+\rho_{12}+\rho_{13}+\rho_{14}+\rho_{15} ; \\
\rho\left(\bar{X}_{1}\right)<\rho\left(\bar{X}_{6}\right) \Rightarrow \bar{X}_{6} \succ \bar{X}_{1} .
\end{gathered}
$$

Так, варіанти $\bar{X}_{i}$ 3 множини $\widetilde{\Omega} \bar{X}$, характеристики $\rho\left(\bar{X}_{i}\right)$ яких не мають великих значень, є компромісами, де за рахунок погіршення одних тактико-техніко-економічних показників досягається покращення, яке відбувається для інших. Різниця між варіантами даної групи полягає у форматі взаємної компенсації змін параметрів.

Навпаки, варіанти $\bar{X}_{i} \in \widetilde{\Omega}_{\bar{X}}, \quad$ у яких величини характеристики $\rho\left(\bar{X}_{i}\right)$ значно більші середнього, мають особливу вагу для ОЗВ при прийнятті обгрунтованого рішення. Саме ці варіанти складу БО здатні забезпечити екстремальні можливості ЛА як зразка озброєння i військової техніки (наприклад, найбільшу дальність визначення цілей, найбільшу номенклатуру засобів ураження для використання, найбільший діапазон умов застосування засобів ураження тощо) $[12,14]$. Для задачі модернізації бойових ЛА саме вибір таких варіантів складу БО є умовою значного підвищення бойових можливостей після модернізації. Тому пропонується упорядкувати варіанти множини Парето за значенням показника (4).

У цьому разі варіанти складу БО 3 найбільшими значеннями даного показника $\rho\left(\bar{X}_{i}\right)$ будуть мати перевагу перед іншими варіантами

$$
\rho\left(\bar{X}_{i}\right)<\rho\left(\bar{X}_{j}\right) \Rightarrow \bar{X}_{j} \succ \bar{X}_{i}
$$

Отже, функція ОЗВ у процесі вибору буде полягати в обранні найбільш перспективного варіанта складу БО із визначених за показником (4) екстремальних варіантів з множини Парето, які ранжовано за виразом (5).

Необхідно зазначити, що це положення $є$ справедливим також для випадку розгляду чебишевської міри замість евклідової (4). 


$$
\left.\rho\left(\bar{X}_{i}\right)=\left(\sum_{j=1}^{\tilde{N}}\left(\begin{array}{c}
R \\
\sum_{k=1}
\end{array}\left(\alpha_{k} \mid J_{k}^{u}\left(\bar{X}_{i}\right)-J_{k}^{u}\left(\left(\bar{X}_{j}\right)\right)\right)^{s}\right)\right)^{\frac{1}{s}}\right) .
$$

Отже, дослідження підтверджує існування теоретичної можливості підвищення обгрунтованості рішення при виборі варіанта складу БО бойового ЛА для його модернізації.

\section{Висновки}

1. Для відшукання області результуючих варіантів складу БО бойових ЛА для їх модернізації використано методологію багатокритеріальної оптимізації, яка дозволяє одночасно враховувати взаємозалежні та суперечливі тактико-технікоекономічні вимоги, що відповідають системі переваг ОЗВ до складу БО бойового ЛА.

2. 3 метою отримання практично важливого рішення задачі багатокритеріального вибору варіантів складу БО бойового ЛА без залучення зовнішньої (суб'єктивної) додаткової інформації для кожного варіанту складу БО, що належить множині Парето $\widetilde{\Omega} \bar{X}$, запропоновано розглядати інтегральну характеристику (4). Ї̈̈ фізичний зміст полягає у тому, що варіанти складу БО з характеристиками, які не володіють умовно “більшими" значеннями, є компромісами, де за рахунок незначного погіршення одних тактико-технікоекономічних характеристик досягається незначне покращення впливу інших. Різниця між такими варіантами полягає у форматі взаємної компенсації зміни характеристик самого БО. Особливо цікавими $є$ такі варіанти складу БО, в яких характеристики (4) значно відрізняються від середніх значень. Саме ці варіанти складу БО можуть забезпечити підвищення бойових можливостей бойових ЛА після їх модернізації.

3. Визначальними особливостями запропонованого методичного підходу щодо визначення результуючої множини варіантів при багатокритеріальному виборі складу БО бойових ЛА для їх модернізації $є$ :

$$
\text { подальший розвиток апарату }
$$

багатокритеріальної оптимізації складних технічних систем (насамперед комплексів спеціалізованого БО), що забезпечує об' єктивне та всебічне оцінювання конкуруючих варіантів складу БО бойових ЛА для їх модернізації; аналітичний алгоритм, де, по-перше, визначається область результуючих варіантів складу БО, які відповідають системі переваг О3В, по-друге, відбувається ранжирування результуючих варіантів БО без залучення зайвої зовнішньої додаткової інформації;

можливість практичної реалізації розробленої методики на сучасній апаратнотехнологічній базі.

$$
\text { 4. Застосування запропонованого }
$$
методичного підходу до багатокритеріального вибору складу БО бойових ЛА для їх модернізації дозволяе подолати негативний вплив зовнішньої інформації на результати вибору та підвищити обгрунтованість результатів такого вибору, але слід враховувати, що ця властивість поширюється лише на випадок вибору варіантів модернізації БО бойових ЛА, тобто зменшення діапазону умов результативного застосування є платою за функціональність спеціалізованих методик.

\section{Список літератури}

1. Кононов О.А. Методичний підхід до вибору складу і розміщення бортового обладнання літальних апаратів військового призначення при їх модернізації /О.А.Кононов, В.Б.Срко // Зб. наук. праць. - К.: ДНДІА, 2016. - № 12 (19). - С. 85 - 90.

2. Єрко В.Б. Особливості застосування методик багатокритеріального вибору варіантів модернізації бортового обладнання літальних апаратів військового призначення /О.А.Кононов, В.Б.Срко // Зб. наук. праць. - К.: ДНДІА, 2017. № $13(20)$. - C. 55 - 59 .

3. Большие технические системы: проектирование и управление/ [Л.М.Артюшин, Ю.К.Зиатдинов, И.А.Попов, А.В.Харченко / под ред. И.А.Попова.] - Харьков: Факт, 1997. - 400 с.

4. Сложные технические и эргатические системы: методы исследования / [А.Н.Воронин, Ю.К.Зиатдинов, А.В.Харченко, В.В.Осташевский.] - Харьков: Факт, 1997. - 240 с.

5. Векторная оптимизация динамических систем / [А.Н.Воронин, Ю.К. Зиатдинов, А.И. Козлов, В.С.Чабанюк / под ред. А.Н.Воронина.] - К.: Техніка, 1999. - 284c.

6. Воронин А.Н. Многокритериальные решения: модели и методы / А.Н.Воронин, Ю.К.Зиатдинов, М.В.Куклинский. - К.:НАУ, 2011. - 348 с.

7. Многокритериальная оптимизация. Математические аспекты. / [Б.А. Березовский, Ю.М. Барышников, В.И. Борзенко, Л.М. Кампнер] - М.: Наука, 1989. - 128 с.

8. Кини Р.Л. Принятие решений при многих критериях: предпочтения и замещения / Р.Л.Кини, Х.Райфа. - М: Радио и связь, 1981. -560 с.

9. Машунин Ю.К. Методы и модели векторной оптимизации / Ю.К.Машунин. - М.: Наука, 1986. - 145 с.

10. Березовский Б.А. Бинарные отношения в многокритериальной оптимизации / Б.А.Березовский, В.И. Борзенко, Л.М. Кампнер. - М.: Наука, 1981. - 150 с.

11. Nakayama, Hirotaka; Yun, Yeboon; Yoon, Min. Sequential Approximate Multiobjective Optimization Using Computational Intelligence (Vector Optimization) (англ.). -Springer. - Р. 2-12. 
12. Гуткин Л.С. Оптимизация радиоэлектронных устройств по совокупности показателей качества / Лев Соломонович Гуткин. - М.:Советское Радио, 1975. - 366 с.

13. Соболь И.М. Выбор оптимальных параметров в задачах со многими критериями. - М.: Дрофа, 2006. - 175 с.

14. Ногин В.Д. Использование набора количественной информации об относительной важности критериев в процессе принятия решений / В.Д. Ногин, И.В. Толстых // Журнал вычислительной математики и математической физики.- 2000, т. 40, - № 11. - С. 1593 - 1601.

15. Steuer, R.E. Multiple Criteria Optimization: Theory, Computations, and Application (англ.). - New York: John Wiley \& Sons, Inc, 1986. - P.4-23.

16. M. Ehrgott, X. Gandibleux. Approximative Solution Methods for Multiobjective Combinatorial Optimization (англ.) // TOP : journal. - Sociedad de Estadística e Investigación Operativa, 2004. - Vol. 12, no. 1.

Надійшла до редколегії 21.10.2021

Схвалена до друку 10.11.2021

Відомості про авторів:

Артюшин Леонід Михайлович

доктор технічних наук

професор

головний науковий співробітник

Державного науково-дослідного інституту авіації,

Київ, Україна

https://orcid.org/0000-0002-7488-7244

Кононов Олексій Анатолійович

доктор технічних наук

доцент

заступник начальника Державного науково-дослідного

інституту авіації,

Київ, Україна

https://orcid.org/0000-0003-2267-9109

\section{Срко Віктор Борисович}

кандидат технічних наук начальник науково-дослідного відділу - заступник начальника науково-дослідного управління Державного науково-дослідного інституту авіації, Київ, Україна

https://orcid.org/0000-0002-5150-5303
Information about the authors:

\author{
Leonid Artushin \\ Doctor of Technical Sciences \\ Professor \\ Chief Researcher \\ of State Research Institute of Aviation \\ Kyiv, Ukraine \\ https://orcid.org/0000-0002-7488-7244
}

\author{
Oleksiy Kononov \\ Doctor of Technical Sciences \\ Associate Professor \\ Deputy Chief \\ of State Research Institute of Aviation \\ Kyiv, Ukraine \\ https://orcid.org/0000-0003-2267-9109
}

\author{
Yerko Viktor \\ Candidate of Technical Sciences \\ Head of Research Department \& Deputy \\ Head of Research Management \\ of State Research Institute of Aviation \\ Kyiv, Ukraine \\ https://orcid.org/0000-0002-5150-5303
}

\title{
DETERMINATION OF THE RESULTING SET OF OPTIONS AT THE MULTI-CRITERIA SELECTION OF THE ONBOARD EQUIPMENT OF COMBAT AIRCRAFT FOR THEIR MODERNIZATION
}

\author{
L. Artushin, O. Kononov, V.Yerko
}

The article identifies the discrepancy between the practical need to ensure the validity of the choice of modern onboard equipment for the modernization of combat aircraft and the limited capabilities of existing selection methods. This determines the relevance of the purpose of this article: the use of scientific and methodological apparatus of multi-criteria choice in determining the composition of the onboard equipment of combat aircraft to expand their combat capabilities through modernization. The authors propose a scientific and methodological approach to determine in the multi-criteria space of the resulting set of variants of the onboard equipment of combat aircraft during their modernization.

The defining features of the proposed methodological approach to determine the resulting set of options for multi-criteria selection of onboard equipment of combat aircraft for their modernization are: further development of multi-criteria optimization of complex technical systems (especially complex onboard equipment), which provides objective and comprehensive evaluation composition of onboard equipment of combat aircraft for their modernization; analytical algorithm, where, firstly, the area of the resulting variants of the onboard equipment is determined, which correspond to the system of preferences of the persons performing the onboard equipment, and secondly, the resulting variants of the onboard equipment are ranked without involving unnecessary external additional information; the possibility of practical implementation of the developed methodology on a modern hardware and technological basis.

The application of the proposed methodological approach to the multi-criteria choice of the onboard equipment of combat aircraft for their modernization allows to overcome the negative impact of external information on the results of the choice and increase the validity of the results of such a choice. But it should be borne in mind that this property applies only to the choice of options for modernization of onboard equipment of combat aircraft because reducing the range of conditions for effective use is a payment for the functionality of specialized techniques.

Keywords: combat aircraft, on-board equipment, modernization, multi-criteria choice, Pareto set. 